\title{
The Effect of Greenhouse Ozone on Human
}

\author{
Valery P. Oktyabrskiy \\ Peter the Great St. Petersburg Polytechnic University, St. Petersburg, Russian \\ Email: vokt@yandex.ru
}

How to cite this paper: Oktyabrskiy, V.P. (2017) The Effect of Greenhouse Ozone on Human. Atmospheric and Climate Sciences, 7, 554-557.

https://doi.org/10.4236/acs.2017.74040

Received: August 24, 2017

Accepted: October 20, 2017

Published: October 23, 2017

Copyright (c) 2017 by author and Scientific Research Publishing Inc. This work is licensed under the Creative Commons Attribution International License (CC BY 4.0).

http://creativecommons.org/licenses/by/4.0/

\section{(c) (i) Open Access}

\begin{abstract}
The article compares the IR absorption spectra of the gases of the Earth's atmosphere with frequencies, close to the frequency of the maximum of thermal radiation of human. It is shown that such a gas is ozone. Being in the transparency window of the atmosphere, it emits absorbed thermal radiation from the Earth. This radiation, in turn, gets to maximum heat absorption (radiation) of a human, and being with it in resonance, fuels him with energy. In larger cities this nourishment is weakened because of the smog due to the strong scattering of Earth radiation and ozone. Thus, the "greenhouse ozone" as a natural source of infrared radiation has beneficial effect on human.
\end{abstract}

\section{Keywords}

Absorption Spectrum, Greenhouse Effect, Greenhouse Ozone

\section{Introduction}

It's known, greenhouse effect (GE) influences on the environment, its climate, and, consequently, on human health. Hence this problem has the special importance for the entire international community. Real processes in the system atmosphere-Earth are different from their usual interpretation due to the solar radiation absorption by overtones and composite frequencies of water vapor of the atmosphere in the visible and near IR region [1]. Thus, the Earth's atmosphere does not act as a greenhouse [2] and used in this case the terms such as GE, greenhouse gas, are purely symbolic. So we will use the term "greenhouse ozone" (GO) in the sense that we are talking about atmospheric ozone, which radiates absorbed thermal emission from the Earth.

To begin, we note that the surface of the Earth, being heated by the Sun through the windows of atmospheric transparency [1] with the average temperature on the surface $290 \mathrm{~K}$, is a source of thermal radiation with a maximum of 10 microns. In this range emit IR sources (IRS, see Table 1), which, as is well 
known [3], have beneficial impact on human. It is known that this range of wavelengths corresponds to thermal radiation (about half the stripe) of the human body with a maximum of $9.4 \mu \mathrm{m}$. Know also that the impact of infrared energy with a wavelength of $9.6 \mu \mathrm{m}$, causes a phenomenon called "resonance absorption" (RA, see Table 1) [4], when the external energy is actively absorbed by the human body. As a result, this exposure increases the potential energy of the body cells, and free water is leaving from them, increases the activity of specific cellular structures, increasing the level of immunoglobulins, increases activity of enzymes and estrogens, there are other favorable biochemical reactions.

The question naturally arises: are there still any natural IR sources in the range close to the maximum heat radiation (absorption) of human. The answer to this question is the subject of this study.

Since this radiation is in the infrared region of the spectra of absorption (emission) of atmospheric gases of the Earth, then consider ones that is closest to it. According to [5], the main role in absorption in the infrared range is played by the molecules of water vapor $\mathrm{H}_{2} \mathrm{O}$ and carbon dioxide $\mathrm{CO}_{2}$. i.e., we can say that the atmosphere is opaque due to the absorption of these gases Earth's thermal radiation at low frequencies up to $900 \mathrm{~cm}^{-1}$. This absorption is due to rotational frequencies of these gases and the deformation oscillation (010) $\mathrm{CO}_{2}(667$ $\mathrm{cm}^{-1}$ ) with a symmetry of $E_{u}$ (perpendicular band) and therefore having a vibrational-rotational spectrum of three branches: P, R and Q. Further, there is the window of transparency (WT, see Table 1), which lies in the middle IR range. And is followed by a region of absorption of deformation vibrations (010) water vapor $\mathrm{H}_{2} \mathrm{O}\left(1595 \mathrm{~cm}^{-1}\right)$. Less impact on the absorption in this region of the molecule nitrous oxide $\mathrm{N}_{2} \mathrm{O}\left(1285 \mathrm{~cm}^{-1}\right)$ and methane $\mathrm{CH}_{4}\left(1300 \mathrm{~cm}^{-1}\right)$. There is a maximum of thermal radiation of human in this WT of the atmosphere and here [5] (Table 1) there is a band of ozone absorption with a half width of about 50 $\mathrm{cm}^{-1}[6]$, the symmetry $A_{1}$ (parallel band), that is the same as that of the oscillations (010) water molecules. As a water molecule non-linear molecule of ozone $\mathrm{O}_{3}$ refers to the point symmetry group $C_{2 v}$, has a dipole moment and therefore has vibrational-rotational spectrum.

The percentage of ozone in the troposphere is less than $0.0001 \%$ of the total volume [7], however, it is necessary to take into account the significant optical thickness of the layer of the troposphere, which is about $10 \mathrm{~km}$. If the maximum intensity of heat radiation (absorption) of the human (see black body spectral radiant emittance, e.g., [8]) at $310 \mathrm{~K}$ is $0.0017 \mathrm{~W} /\left(\mathrm{m}^{2} \cdot \mathrm{cm}^{-1} \cdot \mathrm{sr}\right)$, the maximum value of re-radiation atmospheric ozone is almost an order of magnitude more.

Table 1. Frequencies (F), wavelengths (W) of the maximums of radiation (absorption) of human (310 K), Earth (290K), GO, RA, IRS and WT (see above).

\begin{tabular}{lccccc}
\hline & Human & Earth & GO, RA & IRS & WT \\
\hline $\mathrm{F}, \mathrm{cm}^{-1}$ & 1069 & 1000 & 1042 & $700-1300$ & $900-1200$ \\
$\mathrm{~W}, \mu \mathrm{m}$ & 9.4 & 10 & 9.6 & $8-14$ & $8-11$ \\
\hline
\end{tabular}


This value is obtained from the model re-emission spectrum of atmospheric ozone [6] taking into account the correction factor found from a comparison of the experimental absorption spectrum of ozone in this work, with its model range. Spectra were obtained on the basis of experiments conducted in forest ecosystems of the Middle Urals ( $80 \mathrm{~km}$ from Yekaterinburg).

Thus, based on the foregoing, and also because of the coincidence of the respective frequencies is "resonant absorption", which was mentioned above. In natural conditions the smell of ozone can be felt in places that are rich in oxygen: in the forest, near the sea or waterfall [9]. And, although in larger cities revealed the presence of significant concentrations of ozone anthropo-technogenicproishozheniya [10], it has a large air pollution, and, consequently, strong scattering [11] of the radiation of the Earth and GO. As a result of the contamination of the transparency window of the atmosphere the effectively influence of GO on human, obviously, is much smaller.

To summarize, using the model in the system of atmosphere-Earth, described in [2] we can propose model in which is the impact of the "greenhouse ozone" on the human body:

1) Solar radiation in the range visible and near-IR region, reaching the surface of the Earth through the transparency window [1], heats it to an average of around $290 \mathrm{~K}$;

2) In turn, the Earth radiates heat into the atmosphere;

3) The ozone which is in the atmosphere, absorbing derived from the Earth's thermal emission radiates its in outer space and to the Earth, where this energy is actively absorbed by the human body, being with him in resonance and fueling him.

\section{Conclusions}

Thus, the following conclusions can be drawn from the conducted analysis of the factors about the impact of GO:

1) The impact of the "greenhouse ozone" in the transparency window of the atmosphere, representing a natural form of infrared radiation, similar to the effects of thermal radiation of the Earth and under certain doses of IR emitters in the appropriate range, also is beneficial for human health.

2) This natural form of infrared radiation has the greatest impact on people outside cities: for example, in the forest, by the sea; where is an increased concentration of ozone and the transparency window of the atmosphere is not polluted.

These two conclusions are entirely consistent with human practice: people intuitively try to go in your spare time from the city to the forest, to the sea, where in addition to fresh air and other positive factors there are beneficial natural IR emitters, and it is explained just a desire to feel good and be healthy.

\section{References}

[1] Elyashevich, M.A. (1938) Rotational-Vibrational Energy of the Molecules. Works of 
State Optical Institute, 12, 3-134.

[2] Oktyabrskiy, V.P. (2016) Noviyvzgliydnaparnikoviy effect, NTV SPbSTU. [A New Opinion of 'The Greenhouse Effect'.] Phys-Mat.Science, 2, 82-86.

[3] The IR Rays. Fundamentals of IR Therapy [http://www.ok.ru/], URL 17.08. 2017.

[4] Gvozdenko, L.F. (1999) Obosnovaniedopustimykhnormativovobluchennosti IR izlucheniem v zavisimostiot ego spectralnogosostava. [Rationale for Acceptable Standards of Irradiance Infrared Radiation Depending on Its Spectral Composition.] Publication: Occupational Medicine and Industrial Ecology, 12, 13-18.

[5] Tonkov, M.V. (2001) Spektroskopiyaparnikovogoeffekta. [Greenhouse Effect Spectroscopy.] Soros Educational Journal, 7, 52-58.

[6] Borisov, S.F. (2011) Issledovaniyekharakteristikparnikovykhgazovnaosnovesolnechnoy IK Furye-spektroskopiiipostroyeniyefizicheskikhmodeleyprotsessovteplomassoperenosa v atmosfere. [Study of the Characteristics of Greenhouse Gases, Based on Solar IR Furye Spectroscopy and the Construction of Physical Models of Heat and Mass Transfer Processes in the Atmosphere.] Scientific.-Technical Report. Yekat., 175 p.

[7] The Concentration of Ozone in the Atmosphere. The Borders of the Ozone Layer [http://wonderful-planet.ru/], URL 17.08. 2017.

[8] Characteristics and Use of Infrared Detectors. [http://www.hamamatsu.com/jp/en/index.html], URL 17.08. 2017.

[9] Ozonation [http://www.tiensmed.ru/], URL 14.08. 2017.

[10] Natural Chemical Composition of Atmospheric Ozone [https://studopedia.ru/], URL 14.08. 2017.

[11] Suspended Particles [http://www.ecology-education.ru/], URL 14.08. 2017. 